\title{
Bare Singular NPs in Argument Positions: Restrictions on Indefiniteness*
}

\author{
Ljudmila Geist \\ University of Stuttgart, Germany \\ Ljudmila.Geist@ling.uni-stuttgart.de
}

\begin{abstract}
It has been assumed that in articleless languages such as Russian, bare singular NPs in argument positions can receive a definite or an indefinite interpretation. While the definite interpretation depends on the broader discourse and may freely arise if the referent is familiar, the option of an indefinite interpretation for bare NPs introducing new discourse referents is more restricted. This paper investigates conditions on the indefinite interpretation of bare singular NPs in Russian. It shows that this interpretation is restricted by the topic-comment structure: the indefinite interpretation may arise only if the NP belongs to the comment part of the sentence and is excluded for NPs which are aboutness topics. This restriction can be explained by the requirement that indefinite aboutness topics must be specific. Bare indefinite NPs however can only receive a non-specific existential interpretation, and hence do not qualify as topics. The paper contributes to the elucidation of the interaction between the semantic and pragmatic components of an overall theory of NP interpretation and argues that weak existential NPs should be distinguished from cases of noun incorporation.
\end{abstract}

\section{Keywords}

indefiniteness, topic, weak indefinites, bare NPs, indefinite article

\section{Introduction}

This paper is devoted to the study of bare singular NPs occurring in canonical argument positions. In languages with definite and indefinite articles such as

* This paper has benefited from the opportunity to present it at a conference on Reference and Discourse Structure organized by Sofiana Chiriacescu and Klaus von Heusinger at the University of Stuttgart in January 2010. I wish to thank the conference organizers and conference participants Janette Gundel, Klaus von Heusinger, Stefan Hinterwimmer, Tanja Ionin and Edgar Onea for their helpful comments and fruitful discussion. The comments of two anonymous reviewers helped me to improve the paper. This research was funded by the German Science Foundation (project C2 Case and Referential Context in the SFB 732 Incremental Specification in Context), which I gratefully acknowledge. I would like to thank the editors Klaus von Heusinger and Elsi Kaiser for the inclusion of my paper in this issue. 
English, German or French, such bare NPs formed from singular count nouns are totally impossible in argument positions.

(1) a. *Ann took book.

b. *Ann nahm Buch.

$<$ English $>$

c. *Anne prenait livre.

$<$ German $>$

$<$ French $>$

In some Slavic languages such as Russian, which is generally considered articleless, such bare NPs can be used as arguments:

(2) Anna vzjala knigu <Russian>
Anna took book ACC "Ann took the book/a book".

The well-accepted generalization is that in Russian bare singular NPs do double duty as definites and indefinites. In (2), the bare object NP allows both the definite and the indefinite interpretation depending on the context. If (2) is uttered in a context such as $(3 \mathrm{a})$, which pre-establishes the referent of the book, the bare object NP is the second mention of the referent and gets a definite interpretation. In a context like $(3 b)$, where the referent is not preestablished, the bare NP receives an indefinite interpretation.

(3) a. definite:

(There was a book and a newspaper on the table.) Ann took the book.

b. indefinite:

(Ann usually prefers to read newspapers.) But today Ann took $a$ book.

In English the interpretation of the NP with respect to definiteness is determined by the use of a definite or indefinite article. The question is how bare NPs in Russian get their definite or indefinite interpretation without articles. To answer this question we will follow the standard view that common nouns are predicates of type $\langle e, t\rangle$. Since verbs need arguments of type $\langle e\rangle$ or $\langle\langle e, t\rangle, t\rangle$, this leads to a mismatch, which can be solved by type-shift operations (cf. Partee, 1987). We will make use of two of them, the existential closure operation by the operator $\exists$ and the shifting operation by the iota-operator $t$. The operation of existential closure turns a predicate into an existential generalized quantifier. This is traditionally assumed to be the meaning of the English indefinite article $a$. The iota-operator $\mathrm{s}$ selects the greatest element from the extension of a predicate. This is traditionally taken to be the meaning of the definite article in languages which have one.

While in languages such as English or German the definite and indefinite articles serve as type-shifters, in languages without articles the type-shift operators must be contributed by the sentence context. The definite interpretation 
of the NP arises if the variable is bound by the non-overt iota-operator $\mathrm{t}$. Binding by the existential closure yields an indefinite interpretation of the NP. Given this, we would expect that bare NPs in Russian can always receive a definite or an indefinite interpretation. However, the option of indefinite interpretation which is guaranteed by the use of the indefinite article in a language such as English is not always available for a bare NP in Russian. This point is illustrated in (4) vs. (5). In English, the context in (4a) triggers the use of the definite article because the referent of the NP the girl is pre-established and hence familiar. In context (4b), where the referent of $\mathrm{girl}$ is new, an indefinite article must be used. In Russian the bare NP devochka in (5a) can only receive a definite interpretation. In the context $(5 b)$, which triggers the indefinite interpretation, the bare NP is excluded. The indefinite reading of the NP in this position can be salvaged by explicitly marking it with a quasi-determiner odin "one" or the indefinite pronoun kakoj-to "some", cf. (6a). Odin as the reduced form of the numeral is indicated in the translation as one $\mathrm{R}_{\mathrm{R}}$. Another possibility to save the indefinite reading of the subject is to put it into the postverbal position, as shown in (6b).

(4) a. definite:

(I saw a boy and a girl.)

The girl entered the house.

b. indefinite:

(The door opened and ...) A girl entered the house.

(5) a. definite:

(I saw a boy and a girl.) Devochka voshla v dom.

(the) girl came into (the) house

"The girl entered the house".

b. indefinite:

(The door opened and ...) ${ }^{*}$ Devochka voshla v dom.

(a) girl came into (the) house

(6) a. indefinite:

(The door opened and ...) Odna / kakaja-to devochka voshla v dom. one $_{\mathrm{R}}$ / some girl came into (the) house "A / Some girl entered the house".

b. indefinite:

(The door opened and ...) V dom voshla devochka. into (the) house came (a) girl "A girl entered the house".

This shows that Russian does not freely allow indefinite readings for bare NPs. The examples (5)-(6) suggest that it is the preverbal position which excludes the indefinite interpretation for bare NPs. However, example (7) shows that 
under certain conditions, which must still be elaborated, bare NPs in the preverbal position can also receive an indefinite interpretation.

(7) (Why is it so noisy?)

Rebenok plachet.

(a) child is-crying

"A child is crying".

But if it is not the syntactic position relative to the verb which determines the NP interpretation with respect to indefiniteness, what is it then? The goal of this paper will be to determine the conditions for the indefinite interpretation of bare NPs in Russian and build them into the theory of NP interpretation. To do this we will probe the status of bare indefinite NPs in Russian.

Let us give a brief overview of the paper. In Section 1 we determine the conditions for the definite and indefinite interpretation of bare NPs in Russian. In Section 2 we test the relevance of different information-structural dichotomies for NP interpretation and show that it is the topic-comment structure which restricts the indefinite interpretation of bare NPs. The indefinite interpretation is only available for bare NPs in the comment and is excluded for bare NPs which are topics. The reason for this is presented in Section 3. It lies in the requirement that indefinite aboutness topics must be specific. In Section 4 the concept of specificity is elaborated and it is shown that bare singular NPs under the indefinite interpretation are non-specific. Section 5 examines an alternative view of bare indefinite NPs as incorporated nouns. Section 6 summarizes the paper.

\section{Bare NPs and Determiners}

In this section we will elaborate on the conditions for definite and indefinite interpretation of bare NPs in Russian. Consider first bare NPs interpreted as definite. Under the familiarity view on definiteness (Heim, 1982), the referent of the NP must be familiar to both the speaker and hearer. The familiarity can come about in different ways. As was shown in the introduction, the familiarity can be contributed by previous mention such as in (8), where the bare NP knigu "book" refers to the same book introduced in the previous sentence.

(8) Ha tom stole lezhala kniga i gazeta. Anja vzjala knigu. on that table was-lying (a) book and (a) newspaper Ann took (the) book "A book $\mathrm{i}_{\mathrm{i}}$ and a newspaper were lying on that table. Ann took the book.". 
In example (9) the familiarity of the referent is contributed by the situation in which speaker and hearer are located. In (10) the familiarity of the referent solnce "sun" is based on general knowledge.

(9) My otremontirovali kuchnju.

we renovated (the) kitchen

"We have renovated the kitchen".

(10) Solnce vzoshlo.

(the) sun rose

"The sun rose".

These examples suggest that bare definite NPs in Russian behave as if they have a non-overt definite article. Given that the definite article contributes the iota-operator $\mathrm{l}$, we assume that in Russian, this operator can freely apply to bare NPs with familiar referents to yield the definite interpretation.

Now, consider bare NPs under the indefinite interpretation. While the speaker may be aware of what is being referred to by an indefinite NP, the hearer is not. The core characterization of indefinites in general is that they introduce new referents into the discourse. Such new discourse referents can be anaphorically picked out in the subsequent discourse. In this respect bare NPs in Russian are similar to indefinites with $a$ in English, cf. (11).

(11) Dver' otkrylas'. V dom

(the) door opened into (the) house voshla devochka. Ona molchala.

came (a) girl. she $e_{i}$ said-nothing "The door opened. A girl entered the house. She didn't say anything".

The bare NP devochka "girl" introduces a new discourse referent. The pronoun in the next sentence picks up this referent. Thus, the crucial difference between indefinites and definites is that indefinites introduce a new discourse referent while the discourse referent of definites is already established in the discourse and is hence familiar. We will refer to this condition on the interpretation of NPs as a type of Novelty-Familiarity Condition (cf. a formally different formulation of this condition in Heim, 1982: 369).

\section{Novelty-Familiarity Condition}

An NP is

(i) [+ definite] if its referent is familiar to the speaker and hearer

(ii) [- definite] if its referent is new to the hearer and may be new or familiar to the speaker

Thus, while indefiniteness signals the novelty of the discourse referent associated with the NP, definiteness indicates the familiarity of it. In the next section we will discuss the restrictions on the indefinite interpretation of bare singular NPs. 


\section{Indefiniteness and Information Structure}

\subsection{NP Interpretation and the Theme-Rheme Dichotomy}

As shown in the introduction, bare NPs in Russian do double duty as definites and indefinites. However, while a definite interpretation can arise whenever the Familiarity Condition is fulfilled, the fulfilment of the Novelty Condition does not seem to be sufficient to enable a bare NP to receive an indefinite interpretation. Thus, the indefinite interpretation of bare NPs is subject to certain restrictions. In the literature, various descriptions of these restrictions have been given (cf. the overviews in Brun, 2001, and Hauenschild, 1993). Many scholars point to some dependency of the interpretation of bare NPs on the intonation pattern, word order and the theme-rheme dichotomy.

In Russian, a language with a flexible word order (SVO by default), grammatical roles like subject and object are identified by rich case morphology. This renders overt movement for the identification of grammatical roles in Russian unnecessary. Overt movement is used mainly for purposes of information structure (Junghanns and Zybatow, 1997; King, 1995). Thus in Russian, the word order is determined by information-structural requirements, unlike in English, where the word order serves to identify grammatical roles. What information-structural functions are there in Russian? According to traditional analyses (e.g. Birkenmaier, 1979) two functions can be distinguished: theme and rheme. Following Prague School terminology used by Daneš (1970), the theme can be characterized as the starting point of the utterance and contains old information, while the rheme contributes new information about the theme. In Russian, the word order is determined by information structure in the following way: under stylistically neutral intonation the theme has to precede the rheme. NPs in the theme not explicitly marked for (in)definiteness have to be interpreted as definite. Consider example (13). It gives new information about the location of kniga "book". Kniga is the theme and the rest of the sentence is the rheme. The sentence can be used as a response to the question Where is the book? Note that the subject bare NP in the theme is unstressed and can only receive a definite interpretation. The PP na tom stole "on that table" in the rheme bears the main sentence stress, which is indicated by capital letters.

(13) $[\text { Kniga }]_{\text {Theme }}$ (the $/{ }^{*}$ a) book

[lezhit na tom STOLE $]_{\text {Rheme }}$

is-lying on that table

"The book is lying on that table".

Now consider (14) with an inverse word order. Here the theme position is filled by a prepositional phrase and the subject occurs in the rheme position. 
In this position the subject can receive an indefinite interpretation, which was not available for it in the theme position in (13). Under the indefinite interpretation the NP introduces a new discourse referent. The definite interpretation is also available for the NP. It arises if this NP fulfils the Familiarity Condition, i.e. is linked to an already familiar discourse referent.
$[\mathrm{Na} \text { tom stole }]_{\text {Theme }} \quad[\text { lezhit } \quad \mathrm{KNIGA}]_{\text {Rheme }}$ on that table is-lying (a/the) book
"A/The book is lying on that table".

Note that in the English translation of (14) the word order differs from the word order in Russian. Since in English the word order is generally determined by grammatical roles, the subject a/the book must occur preverbally although it belongs to the rheme.

Consider the characterization of theme and rheme again. In the definition developed by Daneš (1970) within the Prague School, two aspects can be distinguished. We will call them the aboutness aspect and the highlighting aspect. Under the aboutness aspect, theme is something that one is talking about, while rheme is something that is said about the theme. Under the highlighting aspect, rheme is the highlighted part of the utterance bearing the sentence accent; it is the part of the sentence containing a new piece of information. The theme, on the other hand, is normally deaccented; it is the starting point of the utterance and contains old information.

Since in most cases the two aspects coincide, Daneš disregarded the distinction between them. However, we will see that to adequately describe the conditions for indefinite interpretation of bare NPs in Russian we have to separate the aboutness aspect from the highlighting aspect. For this we will split up the theme-rheme structure into two distinct levels of information structure: the topic-comment structure and the focus-background structure (which we will call here background-focus structure). The former structure determines the partitioning of a sentence with respect to aboutness and the latter structure is determined by the aspect of information highlighting. In the next section we will show that these structures do not always coincide and we will test whether the former or the latter structure is relevant for the restriction on the indefinite interpretation of bare NPs.

\subsection{Background-Focus vs. Topic-Comment}

Background-focus and topic-comment are currently assumed to be separate levels of information structure; cf. the overview in Krifka (2007). Let us start 
with the concepts of focus and background involved in the background-focus dichotomy. Highlighting of a constituent in a sentence leads to a partition into a focus (or highlighted) part and a background part. Focused constituents bear a falling pitch contour, $\mathrm{H}^{*} \mathrm{~L}$ (indicated by the cap "I" in (15)). Syntactically the type of focus we assume in this paper is marked by the assignment of the feature $F$ to syntactic words. The words may project this feature to syntactic domains of different sizes such as NPs, VPs and even whole CPs. The domain of focus can be identified by the question-answer method. This method relies on the idea that the focus domain corresponds to the wh-part in the (covert) question suggested by the context. Our example (15a) with the sentence accent on the direct object can serve as an answer to the question Who did John call? or What did John do? In the answer to the former question in (15b), $\mathrm{F}$ projects to the object NP; in the answer to the latter question in (15c), F projects to the whole VP.

(15) a. John called IMAX.

b. John called $\left[\mathrm{MAX}_{\mathrm{F}}\right.$.

c. John $[\text { called } \backslash \mathrm{MAX}]_{\mathrm{F}}$.

Semantically, the constituent in the focus domain indicates a choice from a set of relevant alternatives (Rooth, 1985). In (15b) the set of alternatives established by the focus consists of other individuals John could potentially call. In the utterance $(15 \mathrm{c})$ the set of alternatives includes possible activities John could do such as going for a walk, playing tennis, etc.

The partitioning of a sentence into topic and comment is another level of information structure which can be assumed in addition to the backgroundfocus structure. Generally topics can be identified by prosodic and semantic characteristics. They are marked by a rising pitch contour, $\mathrm{L}^{*} \mathrm{H}$ (indicated by the cap "/" in (16)). Non-contrastive topics are deaccented. Most linguists agree on the semantic concept of the aboutness topic according to which the topic is what the sentence is about. The complement of the topic, the comment, is predicated about the topic. Reinhart (1981) defines aboutness topics as addresses in the common ground, under which the information about the topic - the comment - is stored. The topic-marking of an NP such as in (16a) creates an address for the individual John and the information conveyed by the comment is stored at this address (John is the topic). The proposition conveyed by (16a) can also be conveyed by (16b). However, in (16b) the information is structured differently. (16b) is an utterance about Max, hence the information in the comment should be stored as information about him (Max is the topic). 
(16) a. $[/ \mathrm{John}]_{\mathrm{T}}$ [called $\left.\backslash \mathrm{MAX}\right]_{\mathrm{C}}$.

b. $[/ \mathrm{Max}]_{\mathrm{T}}\left[\right.$ was called by $\mathrm{JJOHN}_{\mathrm{C}}$.

The intuitions about what a particular sentence is about can be made explicit as shown by the aboutness test in Endriss (2009: 40). (16a) can be preceded by the aboutness statement (17a), while for (16b) a natural preceding statement could be (17b). The use of (16a) in the context of (17b) or the use of (16b) in the context of (17a) would be infelicitous.

(17) a. I will tell you something about John.

b. I will tell you something about Max.

Besides this aboutness test and a special pitch contour, topics can be identified syntactically by left-dislocation (Gundel and Fretheim, 2004; Jacobs, 2001, and Reinhart, 1981; among others). The left-dislocation construction contains a demonstrative or personal pronoun which refers back to the topic in the sentence-initial position. In discourse, left-dislocation marks topic change and requires an accent on the topic.

(18) a. $/ \mathrm{JOHN}_{\mathrm{T}}$, he called IMAX.

b. $/ \mathrm{MAX}_{\mathrm{T}}$, he called $\backslash \mathrm{JOHN}$.

In the literature, the topic-comment structure is sometimes mixed up with the background-focus structure. However, these structures are based on different criteria: background-focus structure singles out the highlighted constituent which indicates the presence of alternatives. The topic-comment structure singles out the constituent the sentence is about. In many cases both criteria lead to the same partitioning of the sentence. The examples we discussed above such as (15c) and (16) belong to this type, cf. (19).

(19) (What did John do?)

$[\mathrm{John}]_{\mathrm{T} / \mathrm{B}}[\text { called MAX] }]_{\mathrm{F} / \mathrm{C}^{\circ}}$

The coincidence of the topic with the background and of the focus with the comment such as in (19) is common but not obligatory. There are cases in which the structures do not coincide but just partly overlap. Consider the question-answer pair (20). In B as the answer to A, she is the topic and the rest of the sentence is the comment. The object a novel, which corresponds to the wh-word in the question $A$, is the focus. Unlike in the previous examples, here the focus constituent is just part of the comment.

(20) A: What did $[A n n]_{\mathrm{T}}$ read?

B: $[\text { She }]_{\mathrm{T}}\left[\mathrm{read}[\mathrm{a} \mathrm{NOVEL}]_{\mathrm{F}}\right]_{\mathrm{C}}$. 
In general, topic-comment structures take precedence over background-focus structures. ${ }^{1}$ A special case arises if the topic constituent contains a secondary focus and there is a primary focus outside the topic as in (21). Topics such as these which contain a focus are referred to as contrastive topics (cf. Büring, 2003).

(21) A: What do his children do?

B: $\left[\text { His }[\text { DAUGHTER }]_{\mathrm{F}}\right]_{\mathrm{T}}$ [studies at the UNIVERSITY $]_{\mathrm{C} / \mathrm{F}}$ and $\left[\text { his }[\mathrm{SON}]_{\mathrm{F}}\right]_{\mathrm{T}}$ [goes to $\left.\mathrm{SCHOOL}\right]_{\mathrm{C} / \mathrm{F}}$.

In (21), in the utterance of speaker A a certain set of children has been presupposed and speaker B makes a statement about the two complementary parts of this set, between which a semantic contrast is established. The comment of the sentence coincides with the primary focus constituent.

To conclude, although in many cases the topic and comment coincide with the background and focus, this coincidence need not always be the case. Thus, the two levels of information structure, topic-comment and backgroundfocus, which in the Prague School tradition were captured in one themerheme structure, can be teased apart. In the following we will examine the relevance of the two different structures for the interpretation of indefinite NPs in Russian.

\subsection{Background-Focus and Indefiniteness}

In Russian, the focused constituents normally appear at the right periphery of the clause, cf. Junghanns (2001). Examples (13) repeated in (22) show that the bare NP kniga can only be interpreted as indefinite if it occurs in the focus domain (22b). In (22a) where it is outside the focus domain, the indefinite interpretation is excluded.

(22) a. Kniga (the $/{ }^{*}$ a) book is-lying on that table

"The book is lying on that table".

b. Na tom stole [lezhit KNIGA $]_{\mathrm{F}}$ On that table is-lying (the/a) book

"The/a book is lying on that table".

${ }^{1}$ An exception to this rule is sentences such as (i), where the whole CP is focused and the background part is absent. The focused domain is divided into a topic and a comment.

(i) (What's new?)

$\left[[\text { Ann }]_{\mathrm{T}}[\text { is reading a NOVEL }]_{\mathrm{C}}\right]_{\mathrm{F}}$ 
The observed correlation between the option of indefinite interpretation of bare NPs and their occurrence in the focus domain can be formulated as a constraint on indefinite interpretation. This constraint has the status of a hypothesis we want to test:

\section{(23) Hypothesis I}

Bare NPs in Russian can be interpreted as indefinite only if they are F-marked.

If this hypothesis is correct, an indefinite interpretation of a bare NP will be possible only if it occurs in the focus domain and will be excluded if it belongs to the background. ${ }^{2}$ This hypothesis seems to be right in the contexts discussed so far. However, it runs into problems in other contexts. Consider the question-answer pair in (24). ${ }^{3}$
A: U kogo est' karandash?
'Who has a pencil?'

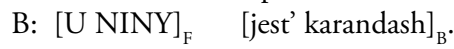
Nina has (a) pencil
"Nina has a pencil".

The NP Nina in the answer correlates with the wh-pronoun in the question. The NP is F-marked. The rest of the sentence, the VP, is background. However, the NP karandash "pencil", although it occurs in the background, preferably receives an indefinite interpretation. This example presents a serious problem for Hypothesis I. Other examples show that this hypothesis is insufficient to capture the restrictions on the indefinite interpretation of bare NPs. Consider example (25):

(25) (What did Mary give the/a boy?)

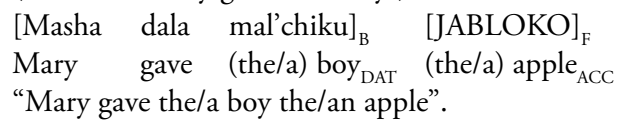

In (25), only the direct object jabloko is in focus. The indirect object mal'chiku, which is outside the focus domain and belongs to the background, can receive either a definite or an indefinite interpretation. Its interpretation depends on the Novelty-Familiarity Condition we defined in (12): if the discourse referent is already familiar, the NP is interpreted as definite; if it is

\footnotetext{
2 A similar situation was described for bare plurals in English, which can get an existential interpretation in the focus domain which, according to Diesing (1992), coincides with the VP.

3 Thanks to Edgar Onea for bringing examples of this type to my attention.
} 
not, the NP receives an indefinite interpretation. It is crucial that for the NP in the background, although the definite interpretation is more likely (Junghanns and Zybatow, 1997: 295), the indefinite interpretation is not excluded. Thus, bare NPs may receive an indefinite interpretation outside the focus domain. The next example shows that even the occurrence of the bare $\mathrm{NP}$ in the focus domain does not always provide the option of indefinite interpretation. In (26) the NP student "student" is in focus, and the background material can be omitted. However, the focused NP cannot receive an indefinite interpretation without the use of an explicit marker of indefiniteness, the unstressed numeral odin. Without odin the NP can only receive a definite reading.

(26) (Who told you this news?)

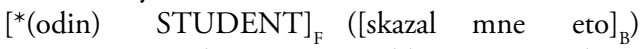

one $_{\mathrm{R}}$ student told $\mathrm{me}_{\mathrm{DAT}}$ this

"A student told me this news".

To conclude, our Hypothesis I, according to which the indefinite interpretation of bare NPs is restricted to the focus domain, is empirically inadequate. On the one hand, bare NPs outside the focus domain, in the background, can be interpreted as indefinite, and on the other hand, even NPs in focus sometimes do not allow an indefinite interpretation. This suggests that the background-focus structure doesn't restrict the indefinite interpretation of bare NPs.

\subsection{Topic-Comment and Indefiniteness}

Having rejected the hypothesis according to which the indefinite interpretation of bare NPs in Russian is restricted to the domain of focus, we will now examine the relevance of another information structural dichotomy, the topic-comment structure. In particular we will test the following alternative hypothesis:

\section{(27) Hypothesis II}

Bare NPs in Russian can be interpreted as indefinite only if they belong to the comment.

To test this hypothesis let us apply the aboutness test introduced in the previous section for the identification of topics to sentence (28). We have seen that in this sentence the bare NP mal'chiku can be interpreted as indefinite although it is outside the focus domain. 
(28) (What did Mary give the/a boy?)

[Masha dala mal'chiku $]_{\mathrm{B}} \quad[\mathrm{JABLOKO}]_{\mathrm{F}}$

Mary gave (the/an) boy ${ }_{\mathrm{DAT}}$ (the/an) apple $\mathrm{ACC}_{\mathrm{ACC}}$

"Mary gave the/a boy the/an apple".

The NP Masha has a rising pitch contour, which is also characteristic for topics in Russian. Intuitively, the sentence tells us something about Masha. This intuition can be made explicit by the aboutness test introduced above. Our example (28) can be preceded by (29a). In this context the sentence sounds natural and tells us something about Masha. If preceded by (29b) or (29c), example (28) sounds less natural and is rather infelicitous. The best way to continue (29b) and to convey the information in (28) is by uttering (30a). And an appropriate continuation of (29c) would be (30b). (30b) would be less natural if preceded by (29a) or (29b).

(29) a. I will tell you something about Masha.

b. I will tell you something about the boy.

c. I will tell you something about the apple.

(30) a. Mal'chiku Masha dala $[\mathrm{JABLOKO}]_{\mathrm{F}}$ (the) boy DAT $_{\text {Mary }}$ NOM gave (the/an) apple $_{\text {ACC }}$

"The boy was given the/an apple by Mary".

b. Jabloko Masha dala [MAL'CHIKU $]_{\mathrm{F}}$

(the) apple $_{\mathrm{ACC}}$ Mary $_{\mathrm{NOM}}$ gave (the/a) boy ${ }_{\mathrm{DAT}}$

"The apple was given the/a boy by Mary".

According to this aboutness test Masha in (28) is the topic and the rest of the sentence is the comment. The syntactic test of left-dislocation, which is also possible in Russian, corroborates this.

(31)

$\begin{aligned} & \text { Masha, ona dala mal'chiku } \\ & \text { Mary she gave } \\ & \text { (the/a) boy }{ }_{\text {DAT }}\end{aligned}$
"Mary gave the/a boy the/an apple".

As a result we can assume the following topic-comment structure for (28):

$$
\begin{array}{llll}
{\left[\text { Masha }_{\mathrm{T}}\right.} & {[\text { dala }} & \text { mal'chiku } & \text { JABLOKO }]_{\mathrm{C}} \\
\text { Mary } & \text { gave } & \text { (the/a) boy }{ }_{\mathrm{DAT}} & \text { (the/an) apple } \mathrm{ACC}_{\mathrm{ACC}}
\end{array}
$$

As indicated in the translation, both objects, the direct jabloko, which is focused, and the indirect mal'chiku, which is in the background, can receive a definite or an indefinite interpretation. Thus, our Hypothesis II, according to which the indefinite interpretation is possible for NPs in the comment, seems 
to be correct. Now, consider the examples of a special type of topic-comment structure in $(33 \mathrm{a} / \mathrm{b})$.

(33) a. A MAN is coming.

b. There is a MAN coming.

Such sentences have been called thetic statements. As opposed to categorical statements, which contain an overt topic in addition to the comment, it has been assumed that thetic statements lack an overt topic and the whole sentence is the comment. The abstract aboutness topic of thetic statements is the situation given in the context (Krifka, 2007; among others). Thetic sentences can be appropriate answers to questions like What happened?, What's the matter? or What's new? and represent instances of focus on the entire utterance. ${ }^{4}$ As Sasse (1987) observes, thetic statements in Germanic, Romance and Slavic languages have special prosodic and syntactic characteristics: while the predicate is deaccented, the subject obligatorily bears the main stress, and can also occur after the inflected verb. In Russian as well, the subject of thetic statements gets the main stress and can occur pre- or postverbally (Junghanns and Zybatow, 1997), cf. (34a/b). Interestingly, in (34a) in the preverbal position, the bare NP subject may be interpreted as indefinite. The definite interpretation is, as usual, available in appropriate contexts.

(34) a. [METEORIT upal $]_{\mathrm{C}}$.

(a) meteorite came-down

"A meteorite came down". b. [Upal

came-down

"A meteorite came down".

Another context which allows NPs in the preverbal position to receive an indefinite interpretation was pointed out to me by Tania Ionin (p.c.), cf. (35).

(35)
$[\text { Ha etoj kartine }]_{\mathrm{T}}$
[devushka
chitaet
PIS'MO] $_{\mathrm{C}}$
in this picture
(a) lady
is-reading
(a) letter
"In this picture, a lady is reading a letter".

The fact that the subject NP devushka "lady" can receive an indefinite interpretation when occurring preverbally fits in with our observation since this NP belongs to the comment. The topic of this sentence is the PP na etoj kartine "in this picture". This is a topic of a special kind, called a frame-topic (Jacobs, 2001). According to Jacobs, frame-topics are not so much what the sentence is about but rather the frame within which the proposition expressed by the

4 The maximal focus on the whole CP is not a specific property of thetic statements. Categorical statements can also bear maximal focus; cf. example (i) in footnote 1. 
sentence holds. In (35) the PP na etoj kartine "in this picture" restricts the proposition expressed by the rest of the sentence.

So far we have seen that bare NPs in the comment can receive an indefinite interpretation irrespective of their position or grammatical role. What we will show next is that bare NPs cannot receive such an interpretation outside the domain of the comment, that is, for bare NPs which function as a topic an indefinite interpretation is excluded.

\section{Indefinite Topics}

\subsection{Indefiniteness and Specificity}

First we have to clear up the question of whether topics in general can be indefinite. While for definites this question does not arise, for indefinites this issue is controversial. According to Gundel and Fretheim (2004), indefinites in English are generally excluded from topic positions except in generic readings. ${ }^{5}$ Other scholars (Cresti, 1995; Endriss, 2009; Reinhart, 1981; among others) assume that indefinites are possible aboutness topics in English and German. Assuming left-dislocation to be a topic-marking device, (36) and (37) from Endriss (2009: 17) represent examples of indefinite aboutness topics in German: ${ }^{6}$

$\begin{array}{llll}\text { /EINEN } & \text { Linguisten, } & \text { den } & \text { kennt IJEDER. } \\ \text { one } & \text { linguist } & \text { res.pron. } & \text { knows everybody }\end{array}$

"One linguist everybody knows".

(37) Ein kleines /MÄDCHEN, das wollte einst nach IFRANKREICH reisen a little girl res.pron wanted once to France travel "Once, a little girl wanted to travel to France".

An example of an indefinite topic similar to (37) is given in (38). This is the beginning of a fairy tale recorded by the brothers Grimm. In the German

${ }^{5}$ In earlier work, Gundel (1985: 88) mentions an exception to this rule. She notes that indefinite topics are possible if they are anchored to a familiar entity such as in (i), where the referent of a daughter is anchored to the expression mine, i.e. to the speaker.

(i) A daughter of a friend of mine, she got her BA in two years.

This restriction on indefinite topics will be explained with a specificity condition later in Section 4 .

${ }^{6}$ In German, left-dislocated topic NPs without modifiers carry an accent on the determiner (Endriss, 2009). 
original the topic is an indefinite NP. In the English translation (39) the topic is indefinite as well. In both languages, when this NP is uttered, it receives a rising pitch contour.

(38) Ein abgedankter Soldat hatte nichts zu leben und wusste sich nicht mehr zu helfen. Da ging er hinaus in den Wald ... (Gebr. Grimm "Des Teufels rußiger Bruder") http://de.wikisource.org/wiki/Des_Teufels_rußiger_Bruder

(39) A disbanded soldier had nothing to live on, and did not know how to get on. So he went out into the forest ... (The brothers Grimm "The Devil's Sooty Brother") http://www.grimmstories.com/en/grimm_fairy-tales/the_devils_sooty

One objection to the analysis of the indefinite subject NPs as topics in these examples could be that such story beginnings represent completely new information and should rather be conceived of as thetic, i.e. as having no overt topic. However the use of stative predicates such as live and know here indicates that this statement cannot be thetic and is indeed categorical. Thetic statements generally contain predicates describing temporary or accidental events (stage-level predicates). Sentences with stative verbs (individual-level predicates) are usually assumed to exclude a thetic interpretation (e.g. Jäger, 2001; Sasse, 1987). ${ }^{7}$ Accordingly, although (38/39) occur at the very beginning of the story, they are categorical and contain an overt aboutness topic. In (39) the indefinite topic a disbanded soldier establishes a new address that points to a place where the information conveyed by the comment will be stored. Consider the topic tests introduced above. Sentences (46/47) can easily be preceded by a sentence establishing aboutness according to the aboutness test: I will tell you something about a disbanded soldier. The leftdislocation of the initial NP analogous to (37) is in principle also possible. However since left-dislocation marks topic change, it is not completely appropriate at the beginning of a story, where no topic has previously been established.

The rising pitch contour as well as the aboutness and left-dislocation tests corroborate the intuition that the indefinite subject NP can serve as aboutness

7 One possible explanation for this is given by Kratzer (1995). She assumes for independent reasons that individual-level predicates, unlike stage-level predicates, have no Davidsonian event argument in their argument structure. However, thetic sentences need a covert event argument as topic, i.e. they can be uttered if an event argument from the main predicate is available to serve as topic. Since individual-level predicates lack an event argument which could serve as a topic, they do not occur in thetic sentences. 
topics. Thus it can be assumed that categorical statements can be used to introduce new discourse referents. Endriss (2009: 34) points to the fact that indefinites behave inconsistently with respect to topicality. Sometimes they seem to be perfect aboutness topics, whereas in other cases, indefinite NPs cannot be felicitously interpreted as topics. An example of an inappropriate indefinite topic is given in (40). The NP a window (with rising topic accent on the noun) cannot occur in the topic position marked by the left-dislocation. Negated indefinites are also excluded in such positions, cf. (41):

(40) *A window, it's still open.

(Gundel, 1988)

(41) *Kein Pferd, das frisst Bananen. "No horse it eats bananas".

(Ebert and Endriss, 2004)

Reinhart (1981) explains the exclusion of some indefinite NPs from topic positions by assuming that topics must be referential in order to provide an entity for an aboutness statement. What Reinhart calls referentiality is called specificity in other approaches. Jacobs (2001) shows that in German only NPs that are specific can turn up in the left-dislocated topic position. Cresti (1995) and Portner and Yabushita (2001) relate topicality to specificity in other languages such as English and Japanese. Although there is no uniform concept of specificity, many scholars agree on the pre-theoretical characteristics of specificity as "identifiability of the referent by the speaker" or "the speaker has a particular referent in mind." For the moment we will assume this pretheoretical concept before we elaborate on the notion of specificity in Section 4. The requirement on NPs which occur as topics can be now summarized in the following condition on indefinite topics:

\section{(42) Condition on Felicitous Indefinite Topics}

Indefinite NPs can serve as aboutness topics if they are specific.

Note that we do not assume that all specific NPs in the sentence must be topics. Specificity is independent of information structure and specific NPs can occur in the comment as well as in the topic position.

Consider again our examples of indefinite topics in (36)-(39) above. The topics in these examples are specific in the sense that they introduce a new referent which the speaker has in mind and can identify. We will illustrate this point with our examples (36) and (39), repeated with continuations in (43) and (44) respectively. In (43), the speaker identifies the referent by naming it. In (44), the speaker refers to the discourse referent introduced by the indefinite topic and then gives more identifying information about it. 
The continuations of both sentences suggest that the speaker has a particular referent in mind.

(43) EINEN Linguisten ${ }_{i}$, den

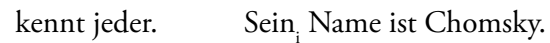
one linguist resump.pron. knows everybody his name is Chomsky "One linguist everybody knows. It is Chomsky".

(44) A disbanded soldier had nothing to live on, and did not know how to get on. So he went out into the forest...

However, in examples in (45) and (46), repeated from (40) and (41) above, the indefinite NPs cannot serve as topics, because they do not fulfil the Condition on Felicitous Indefinite Topics. For a window in (45) the context does not provide a specific discourse referent. In (46) kein Pferd "no horse" does not introduce any discourse referent at all, hence the NP is non-specific.

(45) *A window, it’s still open.

(Gundel, 1988)

(46) *Kein Pferd, das frisst Bananen. (Ebert and Endriss, 2004)

"No horse it eats bananas".

Example (45) improves if more descriptive information is added to the topic NP.

(47) A window that we painted yesterday, it's still open.

To conclude, indefinite NPs are banned from topic positions if they are nonspecific.

\subsection{Indefinite Topics in Russian}

Let us now turn to Russian. The question is whether bare NPs under their indefinite interpretation qualify as topics. To answer this question we can consider the beginning of the fairy tale by the brothers Grimm we discussed above for English and German. In Russian, the indefinite NP is accompanied by the quasi-determiner odin (48a). Without odin the bare NP would be interpreted as definite, thus an indefinite interpretation of the bare NP in the topic position is excluded (48b).

(48) a. Odnomu

otstavnomu soldatu zhit' bylo nechem... one $_{\mathrm{R}}$ disbanded soldier ${ }_{\text {DAT }}$ to-live-on was nothing INS $_{\text {IN }}$ "A disbanded soldier had nothing to live on..."

http://playground.ctp-design.net/grimm-chertov-chumaziybrat.html 
b. Otstavnomu soldatu zhit' bylo nechem ... (the $/^{*}$ a) disbanded soldier $_{\text {DAT }}$ to-live-on was nothing "The disbanded soldier had nothing to live on..."

The initial NP in (48a) is a topic. It has a rising pitch contour and intuitively, the sentence is about what this NP denotes, a disbanded soldier. The sentence could be preceded by I will tell you something about a disbanded soldier. The NP odnomu otstavnomu soldatu can also in principle be left-dislocated, cf. (49). However at the beginning of a story a non-left-dislocated variant would be preferred for the reasons described above for German and English.

(49) Odnomu otstavnomu soldatu, emu zhit' bylo nechem ...

one $_{\mathrm{R}}$ disbanded soldier $_{\mathrm{DAT}}$ he $\mathrm{DAT}_{\mathrm{T}}$ to live on was nothing INS $_{\text {IN }}$

Other examples with indefinite topics corresponding to the examples discussed above for German point in the same direction: an NP in the topic position must be marked by a quasi-determiner odin or in some other way in order to be interpreted as indefinite.

(50)
*(ODNOGO) lingvista, ego
znaet kazhdyj.
one linguist resump.pron. knows everybody

"One linguist everybody knows".

(51) *(Odna) malen'kaja DEVOCHKA, ona chotela otpravit'ja vo Franciju.

one $_{R}$ little girl, resump.pron. wanted travel to France

"Once, a little girl wanted to travel to France".

The quasi-determiner odin is a phonologically reduced form of the numeral word odin "one". According to Ionin (in prep.) odin is a marker of specificity: it indicates that the speaker can identify the referent of the NP or has a particular referent in mind.

The examples discussed above suggest that bare NPs under the indefinite interpretation do not qualify as aboutness topics. If they occur in the topic position, the indefinite interpretation is not possible for them. Thus, our Hypothesis II, according to which the indefinite interpretation is only possible for bare NPs in the comment, is supported. Note that indefinite topics are not in general excluded in Russian, but rather the indefiniteness of these topics must be explicitly marked by lexical means.

As was shown above, restrictions on indefinite topics are also observed in languages with indefinite articles. Plain NPs with an indefinite article do not always satisfy the Condition on Felicitous Indefinite Topics, since not every indefinite NP can easily be interpreted as specific. Fodor and Sag (1982) 
observe a correlation between descriptive richness and specific interpretation of the NP ("referentiality" in terms of Fodor and Sag): the plain NP a student is less likely to be interpreted as specific than the modified NP a student that Betty used to know. This effect is even more pronounced for non-restrictive relative clauses such as in (52) from Fodor and Sag (1982: 361). The additional material in the NP indicates a greater amount of knowledge about the referent on the part of the speaker and hence facilitates the specific interpretation.

(52) A student in the syntax class, who had his Ph.D. in astrophysics, cheated on the exam.

The question is now whether NP-modification as a specificity-favouring device has the same effect in Russian, i.e. enables a specific indefinite interpretation of the bare NP. It has been pointed out in the Slavistic literature that the modification of the NP enables its indefinite interpretation in the topic (theme) position (Birkenmaier, 1979; Hauenschild, 1993); cf. an example from Birkenmaier:

(53) Starucha

$v$ nochnoj kofte otkryla protivopolozhnuju dver' i sprosila ego ... (an) old-woman in pyjamas opened opposite door and asked him

"An old woman in pyjamas opened the opposite door and asked him ..."

Birkenmaier points out that the use of the attribute in example (53) is a precondition for the indefinite interpretation of the NP starucha "old woman" in this position. If the attribute is removed, the indefinite interpretation is not possible (Birkenmaier, 1979: 68). We agree with this intuition. The modification of the initial NP in our soldier-example with a relative clause has the same effect: it enables the specific indefinite interpretation of the topic NP.

(54) Otstavnomu soldatu, |kotoryj ne znal, chem zanjat'sja, |zhit' bylo nechem... (a) disbanded soldier, who didn't know what to do, had nothing to live on "A disbanded soldier, who had nothing to do, had nothing to live on ..."

Note that while in Russian non-modified NPs without indefiniteness markers cannot serve as indefinite aboutness topics, in English non-modified $a$-indefinites in principle qualify as aboutness topics. The modification of $a$-indefinites with additional material just facilitates their specific interpretation and hence better qualifies them for the topic function.

To explain the fact that bare NPs in Russian cannot serve as topics it has to be assumed that they are non-specific. In the next section we will test this hypothesis and provide a formal analysis of bare indefinite NPs in Russian. 


\section{Bare NPs and Specificity}

\subsection{Bare Indefinite NPs and Scope}

In this section we test the scopal behavior of bare indefinite NPs in comparison to indefinites in English. It is known that indefinite singular NPs in English can have narrow or wide scope with respect to intensional/modal operators. In (55) the indefinite NP receives a narrow scope interpretation with continuation 1 , but can receive a wide scope interpretation with continuation 2 .

(55) John wants to marry a French woman.

1. But he doesn't know any yet.

2. He got to know her last summer.

Bare NPs in Russian under their indefinite interpretation only allow the continuation 1 , which indicates narrow scope.

(56) Dzhon hochet zhenit'sja na francuzhenke.

John wants to-marry Prep. (a) French-woman ${ }_{\text {ACC }}$

"John wants to marry a French woman". ${ }^{8}$

1 . But he doesn't know any yet.

2. \#He got to know her last summer.

A wide scope indefinite interpretation can be triggered by using the unstressed numeral odin "one", which according to Ionin (in prep.), serves as a specificity marker.

(57) Dzhon hochet zhenit'sja na odnoj francuzhenke.

John wants to-marry Prep one R $_{\mathrm{R}}$ French-woman $_{\mathrm{ACC}}$.

"John wants to marry a (specific) French woman".

1. \#But he doesn't know any yet.

2. He got to know her last summer.

Thus, bare NPs under their indefinite interpretation differ from indefinites in English since they always take narrow scope with respect to intensional $/$ modal operators.

${ }^{8}$ Note that in this example the definite interpretation of francuzhenka "French woman" is also possible. It can be triggered by a preceding sentence such as Last summer, John got to know a French woman and an Italian woman. Uttered after this sentence the NP in this example gets a wide scope interpretation. 
Further differences between bare indefinite NPs in Russian and indefinites with $a$ in English can be observed with respect to syntactic islands. According to Fodor and Sag (1982) indefinites with $a$ in English can scope out of syntactic islands. Example (58) has a reading with the following paraphrase: John read every book recommended by one particular professor (e.g. Professor Simpson). On this reading the indefinite NP is interpreted outside the scope of the relative clause. The narrow scope reading, under which John read every book that had been recommended by some professor or other, is also available.

(58) a. John read every book that a professor has recommended.
b. wide scope reading:
${ }^{\text {ok }} \mathrm{NP}>\forall$
c. narrow scope reading:
ok $\forall>\mathrm{NP}$

Turning to Russian, example (59) from Ionin (in prep.) shows that the bare $\mathrm{NP}$ has narrow scope and cannot scope out of the island. In contrast, the example in (60) shows that the NP accompanied by the quasi-determiner odin scopes out of the island.

(59) a. Masha chitala kazhduju knigu, kotoruju rekomendoval professor. Mary read every book which recommended (a) professor "Mary read every book that was recommended by some professor or other".

b. " wide scope reading: $\mathrm{NP}>\forall$

c. ${ }^{o k}$ narrow scope reading: $\forall>\mathrm{NP}$

(60) a. Masha chitala kazhduju knigu, kotoruju

Mary read every book which

rekomendoval odin professor.

recommended one $e_{R}$ professor

"Mary read every book that was recommended by a specific professor".

b. ${ }^{o k}$ wide scope reading: odin $\mathrm{NP}>\forall$

c. ${ }^{\#}$ arrow scope reading: $\forall>$ odin $\mathrm{NP}$

The comparison of $a$-indefinites in English with bare indefinites in Russian reveals that the readings of bare indefinites in Russian are a subset of the readings of $a$-indefinites in English. While both can have a narrow scope reading, only $a$-indefinites can also receive a wide scope reading. The scope behaviour of bare indefinite NPs can be summarized in the following generalization:

\section{(61) Scope behaviour of bare indefinite NPs in Russian}

Bare indefinite NPs have narrow scope and cannot scope out of syntactic islands.

In the literature, the non-ability of NPs to escape syntactic islands and to take narrow scope has been equated with non-specificity or non-referentiality, 
while the ability of NPs to escape scope islands and to take wide scope has been equated with specificity or referentiality (Fodor and Sag, 1982; Kratzer, 1998; see also the overview in Ionin, 2010). Since bare indefinite NPs in Russian have narrow scope and cannot scope out of syntactic islands, we assume that they are non-specific. Being non-specific, bare NPs in Russian do not fulfil the Condition on Felicitous Indefinite topics, which must be specific. Thus, the reason why bare NPs cannot serve as aboutness topics is the same as the reason why they have narrow scope in opaque contexts and cannot scope out of syntactic islands: their non-specificity.

\subsection{Specificity and Referential Anchoring}

Next we need to provide a precise account of the semantic status of bare indefinite NPs in Russian. In order to do this, we must introduce our background assumptions concerning the concept of (non-)specificity.

The comparison of the behaviour of $a$-indefinites in English with bare indefinite NPs in Russian in the previous section has shown that unlike bare NPs in Russian, $a$-indefinites can, in addition to narrow scope, also take wide scope and escape syntactic islands. Fodor and Sag (1982) propose capturing such ambivalent behaviour of $a$-indefinites by assuming that they are lexically ambiguous between a referential and a quantificational expression. Thus, the determiner $a$ has two lexical variants, a referential determiner $a\left[a_{\text {ref }}\right]$ and a quantificational determiner $a\left[a_{\text {quant }}\right]$. The combination of these determiners with a common noun gives rise to a particular interpretation of the indefinite NP. Thus, an indefinite such as a professor in (58) can receive two different meanings: one which refers to some specific individual, e.g. Professor Simpson, and one which corresponds to the usual meaning of an existential quantifier $\lambda \mathrm{Q} \exists \mathrm{x}[[\operatorname{professor}(\mathrm{x})] \&[\mathrm{Q}(\mathrm{x})]]$. When the indefinite is interpreted as an existential quantifier, it has the properties of a typical quantifier, i.e. it cannot escape scope islands and has a narrow scope reading. When the indefinite is interpreted referentially, it behaves just like a referential item, i.e. it gives the impression of taking wide scope. What is called referential interpretation in Fodor and Sag's account is what has been referred to as specific interpretation in other accounts. In contrast, what is called quantificational interpretation in Fodor and Sag's account stands for non-specific interpretation in other accounts (e.g. Kratzer, 1998).

Further investigations of indefinites have shown that Fodor and Sag's (1982) view is too simplistic and $a$-indefinites, besides wide scope and narrow scope readings, may also have an intermediate scope reading (cf. Farkas, 1981; Reinhart, 1997, among many others). While $a$-indefinites can receive all three 
readings, there are determiners like a certain which are only compatible with the wide and intermediate scope readings, or indefinites with modified numerals like at least three which are assumed to have only narrow scope (Reinhart, 1997), cf. example (62).

(62) a. Every student read every book that a professor has recommended.

b. wide scope reading: NP $>\forall>\forall$

There exists one professor $\mathrm{x}$ such that every student $\mathrm{y}$ read every book that $\mathrm{x}$ had recommended.

(a certain professor $/{ }^{*}$ at least one professor)

c. intermediate scope reading: $\forall>\mathrm{NP}>\forall$

For every student $\mathrm{y}$, there exists a possibly different professor $\mathrm{x}$, such that $\mathrm{y}$ read every book that $\mathrm{x}$ had recommended.

(a certain professor $/^{*}$ at least one professor)

d. narrow scope reading: $\forall>\forall>\mathrm{NP}$

For every student y, y read every book that some professor or other had recommended.

( ${ }^{*}$ a certain professor / at least one professor)

The availability of two different "specific" readings for $a$-indefinites, the wide scope and the intermediate scope readings, reveals that the assumption of two values of specificity, [+ specific] or [- specific], is not sufficient. Thus, to capture all relevant readings of NPs a more fine-grained structure of specificity has to be assumed. Different mechanisms have been proposed in the literature to account for the wide and intermediate scope specific readings of indefinites in English such as choice function and domain restriction analyses; cf. a comprehensive overview of these analyses in Ionin (2010). Here we will use an account proposed in Onea and Geist (submitted) which builds on the idea advocated in the domain restriction account by Schwarzschild (2002) that indefinites are always existential quantifiers and if an indefinite is specific, the domain of quantification is restricted to a singleton set. In Onea and Geist (submitted) we assume a special kind of domain narrowing to be responsible for specific readings, namely domain narrowing by referential anchoring. The idea of referential anchoring proposed by von Heusinger (2002) is exemplified in example (63). Optionally marked with the specificity marker certain the indefinite a student can have two different readings, one where the speaker has a particular student in mind, and another one where Peter but not the speaker has a particular student in mind.

(63) a. Peter said that a (certain) student cheated on the final exam.

b. Peter said that $a_{\text {speaker }}$ (certain) student cheated on the final exam.

c. Peter said that $a_{\text {Peter }}($ certain) student cheated on the final exam. 
This difference can be described by the term specificity if we assume that specificity is a relative notion: a (certain) student in (63b) is specific relative to the speaker and in (64c) it is specific relative to Peter. Specificity can now be understood as functional dependency between two individuals (von Heusinger, 2002). We model this functional dependency via referential anchoring of one expression to the other by the function variable $f$. The argument on which an indefinite is functionally dependent is its "anchor". In (63b) the anchor is the speaker, while in (63c) the anchor is the subject of the matrix clause Peter. Given this, the following Specificity Condition for NPs can be formulated (cf. von Heusinger, 2002, for a formulation of this condition in terms of referential indices).

\section{(64) Specificity Condition}

An NP introducing a discourse referent $x$ in a sentence $\phi$ is $[+$ specific] if there is a contextually salient function $\mathrm{f}$ such that $\mathrm{x}=\mathrm{f}(\mathrm{y})$ and $\mathrm{y} \in \operatorname{Dom}(\phi)$.

An NP is assumed to be specific if its referent is linked to an already established anchor expression. The anchor must be from the current sentence, rather than from the preceding discourse. In our example (63) the referent of the indefinite can be reconstructed as a function of the speaker $[\mathrm{x}=\mathrm{f}($ speaker$)]$ yielding as "the speaker has a particular student in mind" or the referent can be reconstructed via a function of the matrix subject Peter $[\mathrm{x}=\mathrm{f}($ Peter $)]$ as "a particular student Peter has in mind".

Referential anchoring can now be conceived as a mechanism for narrowing down the domain of quantification for the indefinite to a singleton. We formally implement this domain narrowing in terms of an enrichment operation in (65) that adds a functional dependency into the restrictor of an existential quantifier.

(65) referential anchoring operator

$\mathrm{OP}=\lambda \Phi \lambda \mathrm{P} \lambda \mathrm{Q} \Phi[[\lambda \mathrm{x} . \mathrm{P}(\mathrm{x}) \& \mathbf{x}=\mathbf{f}(\mathbf{y})][\mathrm{Q}]] \quad$ (Onea and Geist, submitted)

where $\mathrm{f}$ and $\mathrm{y}$ are contextually determined

The referential anchoring operator establishes a functional link between the discourse referent $x$ introduced by the NP and some underspecified discourse individual $y$, which is its anchor. The variables $\mathrm{f}$ and $\mathrm{y}$ are contextually bound. For the complex determiner a certain and the referential determiner $a_{\text {ref }}$ in English the referential anchoring operation can be assumed to be part of their lexical entry; cf. the representation in (66a). The anchor y can be referentially bound to the speaker or to another discourse individual like the subject of the clause as shown in example (63) above. For the quantificational article $a_{\text {quant }}$ the representation in $(66 \mathrm{~b})$ can be assumed. The referential anchoring 
operation is not available in its representation, thus the discourse referent $\mathrm{x}$ is not referentially anchored.
(66)
a. $\left[\right.$ a certain $\left./ a_{\text {ref }}\right]: \lambda \mathrm{P} \lambda \mathrm{Q} \exists \mathrm{x}[[\mathrm{P}(\mathrm{x}) \& \mathbf{x}=\mathbf{f}(\mathbf{y})] \&[\mathrm{Q}(\mathrm{x})]]$
b. $\left[a_{\text {quant }}\right]: \lambda \mathrm{P} \lambda \mathrm{Q} \exists \mathrm{x}[[\mathrm{P}(\mathrm{x})] \&[\mathrm{Q}(\mathrm{x})]]$

The referential anchoring mechanism integrated in the lexical entry of specific/referential determiners helps to model scope. It can be assumed that every indefinite NP takes scope below its anchor. Consider (67) in which the NP a certain problem can have a wide or an intermediate scope depending on the anchor chosen.

(67) a. Every student read every book that a (certain) professor has recommended.

b. wide scope reading: NP $>\forall>\forall$

c. intermediate scope reading: $\forall>\mathrm{NP}>\forall$

The wide scope interpretation in (67b) is the result of the binding of the anchor $y$ to the speaker and the specification of the functional relation $x=f(y)$ as "the speaker has $\mathrm{x}$ in mind". The intermediate scope reading $(67 \mathrm{c})$ arises if the anchor is specified by every student. In this case, the professors co-vary with different students and the functional relation can be contextually specified e.g. as "the supervisor of $\mathrm{x}$ ". That is, the anchoring to speech act participants like the speaker, who is outside of the range of any sentential operator, yields a wide scope interpretation of the indefinite. The anchoring to discourse referents in the clause can lead to intermediate scope.

To model the variation within different indefinite determiners in one language and cross-linguistically, we assume that different determiners may lexicalize different constraints on referential anchoring. Turning to Russian, for the specificity determiner odin "one ${ }_{\mathrm{R}}$ " a representation in terms of referential anchoring can be proposed. According to Ionin (in prep.) odin "one ${ }_{\mathrm{R}}$ " indicates that the speaker can identify the referent of the NP or has a particular referent in mind. This can be implemented in the lexical entry of odin in the following way (for other specificity markers in Russian, see Geist, 2008, and Onea and Geist, submitted):

(68) [odin “one ${ }_{\mathrm{R}}$ "]: $\lambda \mathrm{P} \lambda \mathrm{Q} \exists \mathrm{x}[[\mathrm{P}(\mathrm{x}) \& \mathbf{x}=\mathbf{f}($ SPEAKER $)] \&[\mathrm{Q}(\mathrm{x})]]$

According to this representation, odin has two functions: (i) it binds the variable introduced by the NP existentially, and (ii) it anchors the new referent $x$ to the speaker, yielding a specific interpretation of the indefinite. This lexical representation ensures that the anchor for odin-indefinites is always the speaker. The anchoring function can by default be specified as "the speaker can identify x". 
Now consider bare indefinite NPs. We have argued in Section 4.1. that they are non-specific. To capture this fact formally, we assume following Fodor and Sag's analysis of non-specific $a$-indefinites in English that bare indefinite NPs in Russian are existential quantifiers. Thus an NP such as devochka "girl" in the argument position has the non-anchored representation in (69a). Note that bare NPs do not have their own quantificational force. The existential closure is provided by the context (cf. the Introduction). Specificity determiners such as odin, however, provide an existential closure and referential anchoring of the variable, cf. (69b).

(69) a. [devochka "indef. girl" $]_{\mathrm{NP}}: \lambda \mathrm{Q} \exists \mathrm{x}[[\operatorname{girl}(\mathrm{x})] \&[\mathrm{Q}(\mathrm{x})]]$

b. [odna devochka “one ${ }_{\mathrm{R}}$ girl" $_{\mathrm{NP}}=\lambda \mathrm{Q} \exists \mathrm{x}[[\mathrm{P}(\mathrm{x}) \& \mathbf{x}=\mathbf{f}($ speaker $)] \&[\mathrm{Q}(\mathrm{x})]]$

As we have seen in Section 3.2. bare indefinite NPs modified by additional lexical material can serve as topics and hence they receive a specific interpretation. This can be accounted for by assuming that the referential anchoring operator (65) can apply to the existential quantifier in the context restricting the domain of quantification to a singleton. Such a pragmatically enriched existential quantifier receives a specific interpretation and meets the Felicity Condition on Indefinite Topics. Hence, while for modified bare indefinite NPs the referential anchoring is a result of pragmatic enrichment in the context, for indefinite determiners such as odin "one ${ }_{\mathrm{R}}$ " the referential anchoring requirement is part of the lexical entry. Note that an unmodified bare noun without a determiner cannot be referentially anchored.

Let us briefly go back to the English example with an infelicitous indefinite topic in (40), repeated in (70b). We have seen that the indefinite NP a window is not a good topic, but the sentence improves if this NP is modified as in (70b). How can we explain this?

(70) a. *A window, it's still open.

(Gundel, 1988)

b. A window that we painted yesterday, it's still open.

A window must be specific in order to be an appropriate aboutness topic in (70). Hence the noun window must be combined with the referential article $a_{\text {ref }}$ According to the representation (66) this article requires the referent of the NP to be functionally related to an anchor in the discourse by some salient function $\mathrm{f}$. However, the context in (70a) does not provide any specification for this function and no specification of the anchor. This renders the sentence pragmatically infelicitous. Via the modification of the noun in (70b) the speaker provides additional identifying information for the referent. This facilitates the specification of the anchor as the speaker and of the anchoring relation as "the speaker has a particular window in mind", thus rendering the sentence felicitous. 
For the sake of completeness something has to be said about bare definite NPs in Russian. We assume that before they are shifted to argument expressions, bare NPs in Russian are predicates (e.g. Chierchia, 1998); cf. the representation for devochka "girl" in (71a). In examples which facilitate the indefinite interpretation of bare NPs, the operation of existential closure turns the predicate into an existential quantifier yielding (69a), where the predicate expression serves as a restrictor of the quantifier. For NPs interpreted as definite we assume shifting by the iota-operator to an entity as shown in $(71 b)$.

(71) a. $[\text { devochka }]_{\mathrm{N}}: \lambda \mathrm{x}[\operatorname{girl}(\mathrm{x})]$

b. [devochka 'def. girl' $]_{\mathrm{NP}}: \mathrm{ix}[\operatorname{girl}(\mathrm{x})]$

The definite interpretation is available for bare NPs if the Familiarity Condition is fulfilled. An indefinite interpretation is available if the context supports the Novelty Condition.

Taking stock, according to the Condition on Felicitous Indefinite Topics in (42) indefinite NPs can serve as aboutness topics only if they are specific. Since bare indefinite NPs in Russian are non-specific they do not qualify as topics. In the previous section we motivated a view of specificity as referential anchoring. According to the Specificity Condition, an NP is specific if it is referentially anchored to another already established individual in the discourse. From this assumption it follows that only referentially anchored indefinite NPs can serve as topics. 9 The referential anchoring can be established by specificity determiners like odin or by adding additional descriptive material to the NP. A more general question now is why do indefinites need to be referentially anchored to other discourse items in order to qualify as topics? A possible answer could be that referential anchoring as a domain restriction device limits the domain of the existential quantifier to a singleton, restricting possible referents for the NP to a particular individual. Such a restricted existential quantifier can provide an entity for an aboutness statement and hence qualify as a topic. Non-anchored indefinites are not restricted in this sense and are not singletons. Any individual fitting the description can serve as their referent. This seems to disqualify non-specific NPs for the topic function.

9 A similar observation can be found in Comorovski (2008), who for independent reasons assumes that the topic status of indefinite specific subjects in specificational wh-questions can be made possible by their indirect contextual anchoring. Only indefinites that are indirectly contextually anchored to some pre-established discourse individual can function as topics of specificational questions. We think that in other types of clauses indefinite topics have to be anchored too. 


\section{Bare NPs and Incorporation}

In this section we want to discuss an alternative view on Russian data in terms of noun incorporation, which was suggested by an anonymous reviewer. We have shown in this paper that bare singular indefinite NPs have an existential non-specific interpretation and allow only narrow scope readings. These semantic properties have been assumed to be hallmarks of noun incorporation in other languages (Carlson, 2006; Chung and Ladusaw, 2004; Dayal, 2003; Farkas and de Swart, 2004; Van Geenhoven, 1998; among others). Since bare NPs in Russian exhibit these features the question arises whether an incorporation analysis is appropriate for them. Under an incorporation analysis, bare singular NPs in Russian could be assumed to incorporate or not incorporate. When they incorporate, they give rise to an indefinite narrow scope nonspecific interpretation. When they do not, they give rise to a definite interpretation. In what follows we will introduce some background on noun incorporation. Then we will check whether Russian bare singular NPs can be regarded as an instance of incorporation.

\subsection{Properties of Incorporation}

The term noun incorporation has been used when a nominal argument becomes a part of the verb. Noun incorporation can take place at the syntactic and semantic level. In some languages exhibiting incorporation the verb and one of its arguments form a syntactic unit. Compare sentence (72a) where the object noun is a free-standing noun phrase with sentence $(72 b)$ where the noun is incorporated into the verb stem.

(72) Nahuatl (Sapir, 1911, cited in Gerdts, 2001).
a. Ni-c-qza in nacatl.
I-it-eat the flesh
b. Ni-naca-qua
"I eat the flesh".
I-flesh-eat
"I eat flesh".

In general, syntactic incorporation is accompanied by semantic incorporation, under which the NP loses its argument status. While syntactic incorporation always requires semantic incorporation, semantic incorporation can apply without syntactic fusion (Dayal, 2003). Exclusively semantically incorporated NPs may have articles or prepositions and need not be stripped of their morphology. In recent years the interest in semantic incorporation has grown. Some assumptions about semantic properties which were previously assumed to hold generally for all semantically incorporated nouns were relativized. In particular it was shown that incorporated NPs can be modified (Dayal, 2003; 
among others). Moreover the property of discourse transparency which had previously been assumed to be obligatory, was shown not to hold for incorporation cross-linguistically (Mithun, 1984). In their work on Maori, Chung and Ladusaw (2004) show that semantically incorporated nouns allow pronominal anaphors to be linked to incorporated NPs. If the lack of discourse transparency and of modification are not cross-linguistically stable features of noun incorporation then what are its core semantic features? Carlson (2006) suggests a list of cross-linguistically stable properties of semantic incorporation. Besides properties such as (i) indefiniteness; (ii) lack of specificity; (iii) obligatory narrow scope; (iv) existential rather than generic reading; he assumes at least the following properties to be broadly shared by languages exhibiting incorporation: (v) exclusion of individual-level predicates; (vi) number neutrality; (vii) restrictedness. The three latter properties require a more detailed description.

\section{Exclusion of individual-level predicates}

Incorporation is prototypically limited to objects. However, in some languages subject incorporation is also possible. It has been observed that only stagelevel verbs allow the incorporation of subjects. Individual-level verbs or stative predicates do not allow for incorporation of subjects in languages where subjects may in principle incorporate. As Farkas and de Swart (2004) state, Hungarian allows subjects to incorporate, but only if the main verb is a stagelevel predicate, cf. (73a). The incorporation of subjects of individual-level predicates is excluded, $\mathrm{cf}$. (73b)

(73) Hungarian (Farkas and de Swart, 2004)
a. Gyerek sírt
a közelben.
Child cry.Past.III the vicinity.in
"A child was crying in the vicinity".
b. * Gyerek okos.
${ }^{*}$ Child clever

\section{Number neutrality}

Another semantic property of noun incorporation is number neutrality. Although there is no plural morphology on the noun verset "poem ${ }_{\mathrm{ACC}}$ " in (74), there is no singularity implicature. The noun is number neutral in interpretation. There could be one or more poems read.

(74) Hungarian (Farkas and de Swart, 2004)

Mari verset olvas fel.
Mari poem.Acc read.III Part
"Mari poem read aloud" or "Mari is reading aloud a poem/poems/poetry". 


\section{Restrictedness}

Incorporation is subject to idiosyncratic restrictions. Some restrictions concern the verbs which may take incorporated nouns, and others concern the semantic domain of nouns which can undergo incorporation. For example, in Tiwi, body part names can be incorporated. But only three verbs allow these nouns to incorporate: "hit", "grab" and "burn" (Bybee, 1985, cited in Carlson, 2006). With other verbs incorporation is not possible. Another restriction typical for incorporated structures in different languages is a specific noncompositional meaning. The incorporated structure can be limited to an endemic description of a typical activity in some culture. (75) is an example from Dayal (2003) on Hindi:

(75) Hindi (Dayal, 2003)

a. baccaa-khilaanaa "child-looking after"

b. *laRkii-khilaanaa "girl-looking after"

In the description of the socially established activity of looking after children in (75a), the noun is incorporated. No incorporation is possible in (75b), because this activity is not socially established. Another example of a semantically restricted non-compositional meaning are constructions such as being in bed or being in prison in English. These incorporation constructions are not just statements of location. The former construction means "sleeping in bed" and cannot mean e.g. "jumping in bed". The latter construction means "to be incarcerated in prison" and cannot mean "to visit a friend in prison". Such restrictions on meaning are typical for incorporation. Carlson (2006) puts different idiosyncratic restrictions on $\mathrm{V}-\mathrm{N}$ combinations together under the term restrictedness.

Many linguists agree that the features including indefiniteness, obligatory narrow scope and number neutrality are cross-linguistically significant for noun incorporation. However, as Carlson (2006) states, indefiniteness, lack of specificity, obligatory narrow scope and existential reading can be found in some unincorporated structures such as bare plurals in English. Dayal (2003) points out that weak indefinites are similar to incorporated nouns and share these features with them. However, she claims that unlike incorporated nouns weak indefinites do not exhibit number neutrality. For this reason weak indefinites cannot be conflated with noun incorporation (contra assumptions in Van Geenhoven, 1998). Dayal illustrates this point with Hindi. In this language, weak NPs and incorporated NPs are bare, have indefinite existential reading, always receive non-specific interpretation and have obligatory narrow scope. An example which shows the difference between weak indefinites and incorporated nouns in Hindi is given in $(76 \mathrm{a} / \mathrm{b})$. 
(76) Hindi (Dayal, 2003)

a. anu puure din cuuhad pakaRtii rahii
Anu whole day mouse kept-catching
"Anu kept catching mice (different ones) the whole day".
b. puure din kamr meN cuuhaa ghustaa rahaa
whole day room in mouse kept-entering
"The whole day a mouse (the same one) kept entering the room".

The bare singular object cuuhaa "mouse" in (76a) has a number neutral interpretation and according to Dayal (2003) it is incorporated. In (76b) however, the bare singular subject can only be interpreted as singular. Since this NP is not number neutral, but has a singularity implicature, Dayal assumes that it is not incorporated. From this it can be concluded that incorporated nouns should be kept distinct from weak indefinites.

\subsection{Against an Incorporation Analysis in Russian}

With this background, let us now consider the evidence that shows that bare indefinite NPs in Russian are not incorporated.

The first question is whether Russian exhibits syntactic incorporation with respect to bare indefinite NPs. The answer is: no. In Russian, bare NPs with an indefinite interpretation are syntactically independent units. There is no restriction on particular syntactic positions or grammatical role: as we have shown in this paper, direct and indirect objects (cf. (1) and (28)) but also subjects in the comment part of the sentence ((34) and (35)) can receive an indefinite interpretation. However, although there are no grounds for assuming the syntactic incorporation of bare NPs in Russian, semantic incorporation could in principle still be possible because it can apply independently of syntactic incorporation. We have already seen that bare indefinite NPs in Russian are non-specific, have narrow scope and always receive existential interpretation. In what follows we will check whether Russian exhibits other properties of incorporated nouns proposed by Carlson (2006): exclusion of individual-level predicates, number neutrality and restrictedness.

\section{Exclusion of individual-level predicates}

It is known that individual-level or stative predicates do not allow the incorporation of subjects. However, it is also known that weak NPs such as bare plurals in English ${ }^{10}$ cannot serve as subjects of such predicates, either (Diesing,

${ }^{10}$ We follow Carlson (2006) in assuming that bare plurals in English are unincorporated structures. Although it is controversial whether they can be considered as number neutral or not 
1992; Kratzer, 1995; among others). In the subject position of individuallevel predicates they cannot have existential weak interpretation, but only a strong generic reading.

(77) a. Firemen are altruistic.

(Diesing, 1992)

b. "existential interpretation: "Typically, there are altruistic firemen".

c. okgeneric interpretation: "Firemen are typically altruistic".

In Section 3.1. we have shown that this restriction on subjects of individuallevel predicates has to do with information structure. Individual-level predicates can only occur in categorical sentences, i.e. sentences with overt topics. Since topics must be specific and in English, subjects are normally topics, weak NP subjects, which are non-specific, are excluded in such sentences. Russian exhibits a similar picture: if a bare NP occurs in the topic position of a sentence with an individual-level predicate, it cannot receive a weak existential interpretation. It is either interpreted as generic or as definite.

(78) a. Student

znaet japonskij jazyk.

(the/*a) student

knows Japanese language

b. "existential interpretation: "Typically, there is a student who knows Japanese".

c. generic interpretation: "A student typically knows Japanese".

d. definite interpretation: "The student (we spoke about yesterday) knows Japanese".

To conclude this point, in Russian bare existential NPs cannot serve as preverbal subjects of individual-level predicates. However, this doesn't mean that such NPs are incorporated. Weak non-incorporated NPs in English are excluded in this position, too. Thus, the exclusion of NPs in this position is not a reliable test for incorporation.

\section{Number neutrality}

Number neutrality is a feature of incorporated nominals that, according to Dayal (2003), holds cross-linguistically. But what about Russian? Consider example (79) (=2) with the object NP under the indefinite interpretation.

(79)
Anna vzjala
knigu.
Anna took
"Ann took a book".
(a) book $_{\mathrm{ACC}}$

The NP knigu "book" is morphologically singular since it lacks plural morphology. Generally, the lack of plural morphology on count nouns in Russian

they do not exhibit the feature of restrictedness: there are no restrictions on their appearance or combination with verbs. 
gives rise to a singularity implicature. The bare NP in (79) can only receive a singular interpretation.

\section{Restrictedness}

Incorporation structures are subject to idiosyncratic restrictions, their meaning is often non-compositional. As far as we know there are no idiosyncratic restrictions on the combination $\mathrm{V}-\mathrm{N}$ for bare singulars in Russian. All verbs which in principle allow indefinite arguments can take indefinite bare NPs as their arguments. There is also no restriction on noun classes, since every count noun can be used as a bare singular NP with indefinite interpretation. No systematic restrictions have been observed at the level of meaning composition, either. The meaning of constructions consisting of a verb and a bare indefinite NP is strictly compositional.

To conclude this section, the syntactic independency of bare singular NPs under indefinite interpretation in Russian points against syntactic incorporation. Furthermore, indefinite bare NPs also do not exhibit semantic properties which are found exclusively in incorporation such as number neutrality and restrictedness. Thus, there are no grounds for assuming that bare indefinite NPs are incorporated. They are just weak NPs. We follow Carlson (2006) and Dayal $(1999,2004)$ assuming that noun incorporation and weak indefinites are distinct phenomena.

\section{Summary and Outlook}

The starting point of this paper was the observation that in articleless languages such as Russian bare singular NPs can receive a definite or an indefinite interpretation. However, while the definite interpretation of bare NPs arises under the same conditions under which the definite article is used in English or German, the option of an indefinite interpretation of bare NPs is restricted. Where an indefinite interpretation of an NP as indicated by an indefinite article is possible in English, such an interpretation is sometimes excluded for bare NPs in Russian. We considered the relevance of different informationstructural dichotomies such as theme-rheme, topic-comment and backgroundfocus and identified the following condition on the indefinite interpretation of bare NPs in this language: bare singular NPs can be interpreted as indefinite only if they belong to the comment. The occurrence in the topic position prevents their indefinite interpretation.

We accounted for this fact by arguing that bare indefinite NPs have a nonspecific reference. Indefinite aboutness topic NPs, however, must be specific in 
order to provide a particular entity for an aboutness statement. Being nonspecific, bare singular indefinite NPs do not qualify as aboutness topics. Specificity was understood in this paper in the sense of referential anchoring: specific indefinites introduce a new discourse referent anchored to the speaker or to another discourse individual. Non-specific indefinites are not anchored and can be analyzed as plain existential quantifiers. Specific interpretation of bare indefinite NPs can be achieved by adding specificity markers like odin or descriptive material to the NP. Such enrichment of bare NPs triggers referential anchoring to the speaker, and hence specificity, and enables their occurrence as aboutness topics.

We have shown that bare NPs under their indefinite interpretation have narrow scope and cannot scope out of syntactic islands. They share these properties with incorporated nouns in languages exhibiting noun incorporation. Since however bare NPs in Russian do not exhibit other properties of incorporation which do not hold for weak NPs such as number neutrality and restrictedness, we assume that they are not instances of incorporation.

Restrictions on indefinite existential interpretation similar to those discussed in this paper for Russian have been observed for bare singular (non-incorporated) NPs in Hindi (Dayal, 1999, 2004) and for bare plurals in English and German (e.g. Diesing, 1992). It should be tested whether the formulation of restrictions on the indefinite existential interpretation of bare NPs in terms of topic-comment structure we proposed in this paper can better capture the restrictions on the existential interpretation of bare NPs in these languages.

\section{References}

Birkenmaier, Willy. 1979. Artikelfunktionen in einer artikellosen Sprache. Studien zur nominalen Determination im Russischen. München: Fink.

Brun, Dina. 2001. Information structure and the status of NP in Russian. Theoretical Linguistics 27: $109-135$.

Büring, Daniel. 2003. On D-trees, Beans, and B-accents. Linguistics and Philosophy 26: $511-545$.

Bybee, Joan 1985. Morphology: A Study of the Relation between Meaning and Form. Philadelphia: John Benjamins.

Carlson, Greg. 2006. The meaningful bounds of incorporation. In S. Vogeleer and L. Tasmowski (eds.), Non-Definiteness and Plurality, 35-50. Amsterdam: John Benjamins.

Chierchia, Gennaro. 1998. Reference to kinds across languages. Natural Language Semantics 6: $339-405$.

Chung, Sandra and William Ladusaw. 2004. Restriction and Saturation. Cambridge, MA: MIT Press.

Comorovski, Ileana. 2008. Intensional subjects and indirect contextual anchoring. In J. Guéron and J. Lecarme (eds.), Time and Modality, 39-57. Dordrecht: Springer. 
Cresti, Diana. 1995. Indefinite Topics. PhD dissertation, Massachusetts Institute of Technology.

Daneš, Frantisek. 1970. One instance of the Prague school methodology: functional analysis of utterance and text. In P. Garvin (ed.), Method and Theory in Linguistics, 132-146. The Hague: Mouton.

Dayal, Veneeta. 1999. Bare NP's, reference to kinds, and incorporation. Proceedings of SALT IX, 35-51. Ithaca, NY: Cornell University Press.

Dayal, Veneeta. 2003. A semantics for pseudo-incorporation. Unpublished ms, Rutgers University.

Dayal, Veneeta. 2004. Number marking and (in)definiteness in kind terms. Linguistics and Philosophy 27: 393-450.

Diesing, Molly. 1992. Indefinites. Cambridge, MA: MIT Press.

Ebert, Christian and Cornelia Endriss. 2004. Topic interpretation and wide scope indefinites. Proceedings of the NELS 34, 203-214. Amherst: GLSA.

Endriss, Cornelia. 2009. Quantificational Topics - A Scopal Treatment of Exceptional Wide Scope Phenomena. Dordrecht: Springer.

Farkas, Donka. 1981. Quantifier scope and syntactic islands. Proceedings of CLS 7, 59-66. Ithaca, NY: Cornell University Press.

Farkas, Donka and Henriëtte de Swart. 2004. Incorporation, plurality, and the incorporation of plurals: a dynamic approach. Catalan Journal of Linguistics 3: 45-73.

Fodor, Janet and Ivan Sag. 1982. Referential and quantificational indefinites. Linguistics and Philosophy 5: 355-398.

Geist, Ljudmila. 2008. Specificity as referential anchoring: evidence from Russian. Proceedings of SuB12, 151-164. Oslo: ILOS.

Gerdts, Donna. 2001. Incorporation. In A. Spencer and A. Zwicky (eds.), The Handbook of Morphology, 84-100. Oxford: Blackwell.

Gundel, Jeanette. 1985. 'Shared knowledge' and topicality. Journal of Pragmatics 9: 83-107.

Gundel, Jeanette. 1988. Universals of topic-comment structure. In M. Hammond, A. Moravcsik and J. Wirth (eds.), Studies in Syntactic Typology, 209-239. Amsterdam: John Benjamins.

Gundel, Jeanette and Thorstein Fretheim. 2004. Topic and focus. In L. Horn and G. Ward (eds.), Handbook of Pragmatics, 174-196. Malden, MA: Blackwell.

Hauenschild, Christa. 1993. Definitheit. In J. Jacobs and A. von Stechow (eds.), Syntax: An International Handbook of Contemporary Research, 988-998. Berlin: Walter de Gruyter.

Heim, Irene. 1982. The Semantics of Definite and Indefinite Noun Phrases. PhD dissertation, University of Massachusetts, Amherst.

von Heusinger, Klaus. 2002. Specificity and definiteness in sentence and discourse structure. Journal of Semantics 19: 245-274.

Ionin, Tania. in prep. Pragmatic Variation among Specificity Markers.

Ionin, Tania. 2010. An experimental study on the scope of (un)modified indefinites. International Review of Pragmatics 2: 228-265.

Jacobs, Joachim. 2001. The dimensions of topic-comment. Linguistics 39: 641-681.

Jäger, Gerhard. 2001. Topic-comment structure and the contrast between stage level and individual level predicates. Journal of Semantics 18: 83-126.

Junghanns, Uwe. 2001. On rightward backgrounding. In G. Zybatow, U. Junghanns, G. Mehlhorn and L. Szucsich (eds.), Current Issues in Formal Slavic Linguistics, 329-343. Frankfurt am Main: Peter Lang.

Junghanns, Uwe and Gerhild Zybatow. 1997. Syntax and information structure of Russian clauses. In W. Brown (ed.), Formal Approaches to Slavic Linguistics \#4: The Cornell Meeting, 289-319. Ann Arbor: Michigan Slavic Publications.

King, Tracy. 1995. Configuring Topic and Focus in Russian. PhD dissertation, Stanford University. 
Kratzer, Angelika. 1995. Stage-level and individual-level predicates. In G. Carlson and F.J. Pelletier (eds.), The Generic Book, 125-175. Chicago: The University of Chicago Press. Kratzer, Angelika. 1998. Scope or pseudo-scope: are there wide-scope indefinites? In S. Rothstein (ed.), Events in Grammar, 163-196. Dordrecht: Kluwer.

Krifka, Manfred. 2007. Basic notions of information structure. In C. Féry, G. Fanselow and M. Krifka (eds.), The Notions of Information Structure, 13-55. Potsdam: Universitätsverlag.

Mithun, Marianne. 1984. The evolution of noun incorporation. Language 62: 847-894.

Onea, Edgar and Ljudmila Geist. submitted. Indefinite determiners and referential anchoring. Journal of Semantics.

Partee, Barbara. 1987. Noun phrase interpretation and type-shifting principles. In J. Groenendijk, D. de Jongh and M. Stokhof (eds.), Studies in Discourse Representation Theory and the Theory of Generalized Quantifiers, 115-143. Dordrecht: Foris.

Portner, Paul and Katsuhiko Yabushita. 2001. Specific indefinites and the information structure. Theory of topics. Journal of Semantics 18: 221-297.

Reinhart, Tanya. 1981. Pragmatics and linguistics. An analysis of sentence topics. Philosophica 27: 53-94.

Reinhart, Tanya. 1997. Quantifier scope: how labor is divided between QR and choice functions. Linguistics and Philosophy 20: 335-397.

Rooth, Mats. 1985. Association with Focus. PhD dissertation, University of Massachusetts, Amherst.

Sapir, Edward. 1911. Some aspects of Nootka language and culture. American Anthropologist 13: $15-28$.

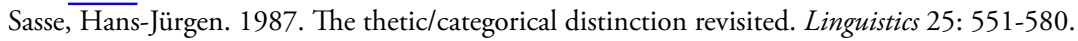

Schwarzschild, Roger. 2002. Singleton indefinites. Journal of Semantics 19: 289-314.

Van Geenhoven, Veerle. 1998. Semantic Incorporation and Indefinite Descriptions. Semantic and Syntactic Aspects of Noun Incorporation in West Greenlandic. Stanford: CSLI Publications. 